\title{
Intrapulmonary metastasis from primary pulmonary meningioma presenting as multiple cystic lesions: a case report
}

\author{
Xin Wang ${ }^{1+}$, Pengfei $\mathrm{Li}^{1 \dagger}$, Ping Zhou ${ }^{2}$, Yiyun Fu${ }^{2}$, Yutian Lai ${ }^{1}$ and Guowei Che ${ }^{1 *}$ (D
}

\begin{abstract}
Background: Cystic lung lesions involving both lungs include a variety of diseases, such as pulmonary Langerhans cell histiocytosis, lymphangioleiomyomatosis and pulmonary metastasis. Primary pulmonary meningioma accompanied with intrapulmonary metastasis was extremely rare and we were not aware of previous studies reporting with cystic radiological manifestation.

Case presentation: A 64-year-old female patient was admitted to our department for a mass located in right posterior mediastinum with multiple cystic pulmonary lesions. A thoracoscopic lung biopsy was performed and the diagnosis was confirmed as bilateral pulmonary metastasis from primary pulmonary meningioma.

Conclusions: Intrapulmonary metastasis from a primary pulmonary meningioma may manifest as multiple thinwalled cystic lesions on computed tomography. Differential diagnosis of cystic pulmonary disease should include this situation. Our case shows the new CT manifestation of metastatic primary pulmonary meningioma and the importance of immunomolecular analysis.
\end{abstract}

Keywords: Pulmonary meningioma, Computed tomography, Cystic, Metastasis

\section{Background}

Cystic lung lesions involving both lungs include a variety of diseases, such as pulmonary Langerhans cell histiocytosis, lymphangioleiomyomatosis, Birt Hogg Dubé syndrome and pulmonary metastasis [1]. Meningioma might occur in extracranial organs and pulmonary meningioma is the most reported since it introduced by Weiss et al. in 1952 [2]. The primary pulmonary meningioma (PPM) with metastasis was extremely rare, which usually presented as isolated nodules rather than bilateral lesions. We describe a patient with one major lesion and multiple cystic lesions scattered over both lungs. The major mass was diagnosed as primary pulmonary meningioma and other cystic lesions was classified as intrapulmonary metastasis after thoracoscopic surgery.

\footnotetext{
* Correspondence: cheguowei_hx@aliyun.com

${ }^{+}$Xin Wang and Pengfei Li contributed equally to this work.

${ }^{1}$ Department of Thoracic Surgery, West China Hospital, Sichuan University,

Chengdu 610041, People's Republic of China

Full list of author information is available at the end of the article
}

\section{Case report}

A 64-year-old female patient was admitted to our department for multiple pulmonary lesions discovered by health examination for 1 month. She was asymptomatic, in good health, and had no history of pulmonary or neurologic disease. She denied history of tuberculosis, and she was a non-smoker.

Chest computed tomography (CT) revealed multiple thin-, smooth-walled cysts or cystic nodules with solid component were scarred within the lung parenchyma, sized from $0.8 \mathrm{~cm}$ to $2 \mathrm{~cm}$ (Fig. 1a, c). Enhanced CT scan revealed a $3.4 \mathrm{~cm}(\mathrm{~cm})$ rounded mass located in the right posterior mediastinum at the inferior pulmonary vein plane (Fig. 1b). It showed slight enhancement in the enhanced CT scan. The result of preoperative brain magnetic resonance imaging was also negative.

Thoracoscopic lung resection was scheduled for this patient. During the operation, the larger mass, which

C The Author(s). 2019 Open Access This article is distributed under the terms of the Creative Commons Attribution 4.0 International License (http://creativecommons.org/licenses/by/4.0/), which permits unrestricted use, distribution, and reproduction in any medium, provided you give appropriate credit to the original author(s) and the source, provide a link to the Creative Commons license, and indicate if changes were made. The Creative Commons Public Domain Dedication waiver (http://creativecommons.org/publicdomain/zero/1.0/) applies to the data made available in this article, unless otherwise stated. 

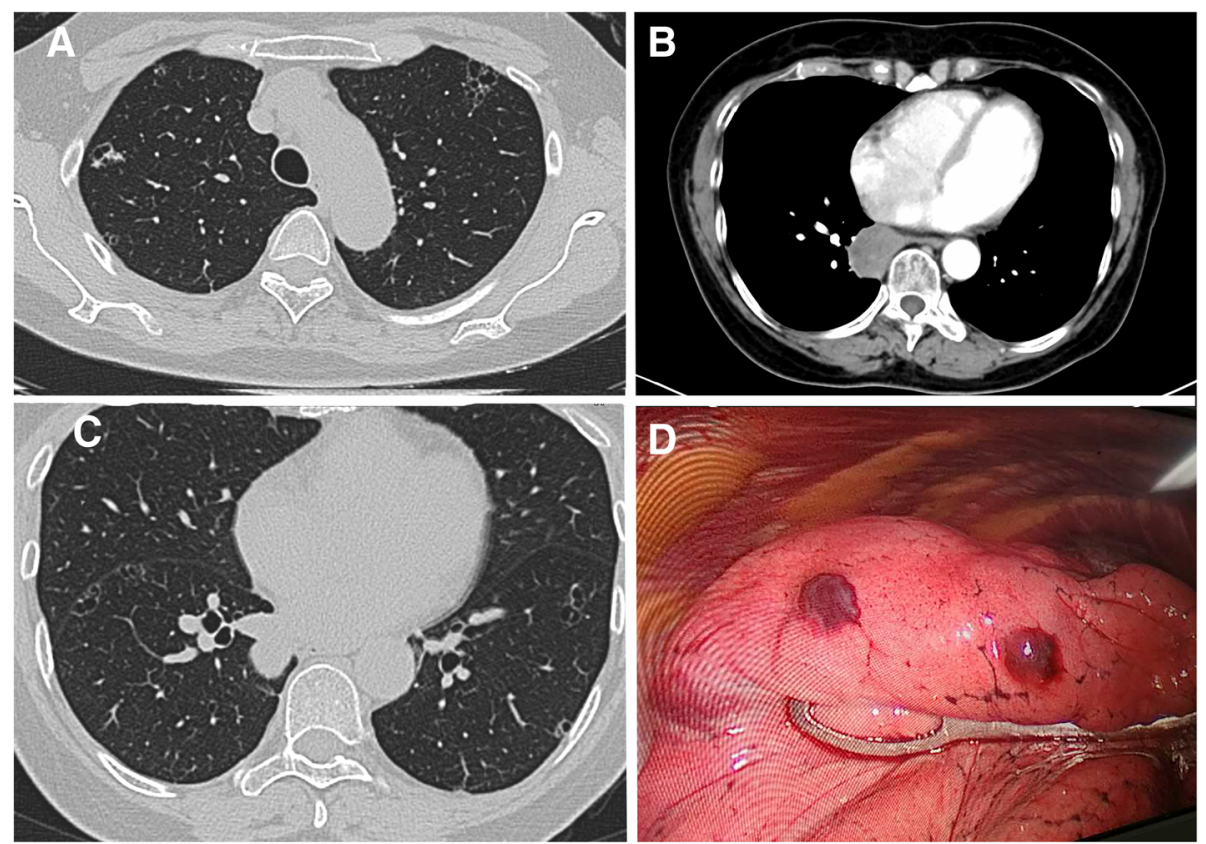

Fig. 1 a, c: CT revealed multiple cycstic lesions involving both lungs. b: Major mass located in the right posterior mediastinum. d: Lung biopsy was taken for pathological examination

enveloped by fat-like thin films, was located on the surface of right lower lobe rather than the mediastinum. The tumor was stripped out successfully with a right-angle electrode and we also wedge resected two cystic lesions for pathological examination (Fig. 1d).

Routine pathological examination of both major mass and cystic lesions revealed the tumor consisting of spindle cells arranged in swirls scattered with a small amount of typical psammoma body (Fig. 2a, b, c hematoxylin and eosin staining, X100). Immunohistochemical (IHC) staining was performed for both major mass and cystic lesions and all lesions were positive for epithelial membrane antigen (Fig. 2d, X200), CD34(Fig. 2e, X100), progesterone receptor (PR), Ki-67 and negative for STAT6 and CD68. The Ki-67/MIB-1 labeling index was less than 2\% (Fig. 2f, X200).

The patient underwent an uneventful postoperative course and no additional therapy was added for her.

\section{Conclusion}

Intrapulmonary metastasis from a primary pulmonary meningioma may manifest as multiple thin-walled cystic lesions on computed tomography. Differential diagnosis of cystic pulmonary disease should include this situation. Our case shows the new CT manifestation of metastatic primary pulmonary meningioma and the importance of immunomolecular analysis.

\section{Discussion}

The diagnosis of the PPM depends on pathological and radiological studies, and more importantly, excluding metastasis from central nervous system. It is frequently reported that intracranial meningioma could metastases to the lungs, but only one case reporting multiple primary pulmonary meningioma [3]. The radiology manifestation of almost all of the metastasis or primary pulmonary meningioma showed as well-circumscribed solid nodules or mass $[4,5]$. We are not aware of previous reports of intrapulmonary metastasis from primary pulmonary meningioma presenting as multiple thin-walled cystic lesions scattered within the lung parenchyma.

The initial diagnosis of this patient was considered as mediastinal tumor with multiple thin-walled cysts involving bilateral lungs based on chest CT. These thin-walled cysts were suspected to be lymphangioleiomyomatosis or Langerhans cell histiocytosis for their radiology manifestations. Morphological and histological characters ruled out the possibility of lymphangioleiomyomatosis. And negative expression of IHC staining of CD68 ruled out the diagnosis of Langerhans cell histiocytosis. Other IHC markers, such as KI67/MIB-1, CD34 and $\mathrm{PR}$ evaluated at the same time because these markers are correlated with recurrence and metastasis ${ }^{4}$. The results of pathology examination suggested to be benign primary pulmonary meningioma, however, even benign meningioma could metastasize [6]. And of these 

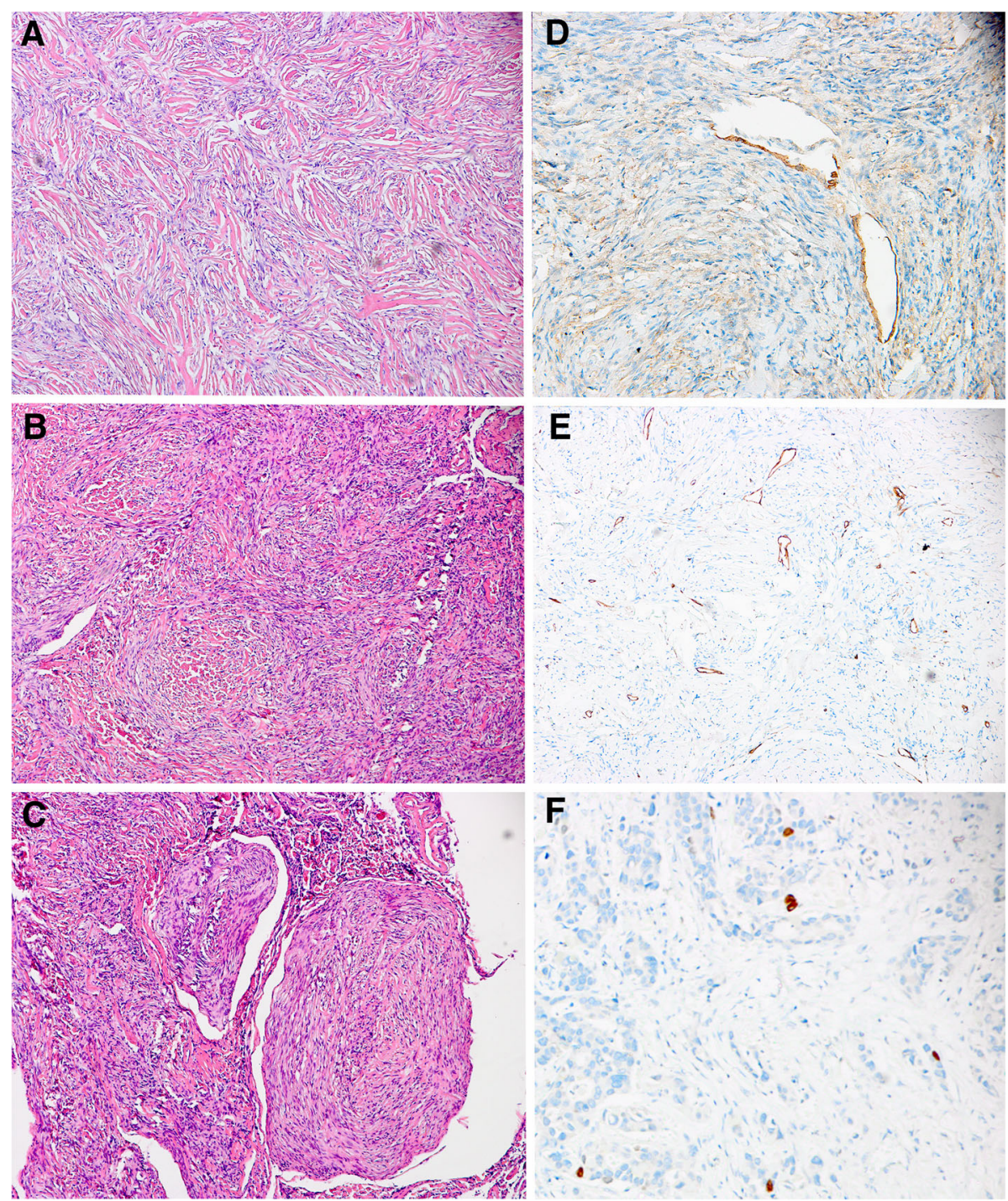

Fig. 2 a, b, c: Tumor consisted of spindle cells arranged in swirls, Hematoxylin \& eosin, $\times 100$. d: IHC staining of EMA was positive, X200. e: IHC staining of CD34 was positive, X100. $\mathbf{f}$ : $\mathrm{HC}$ staining of Ki-67/MIB-1 was positive, X200

rare metastatic benign diseases, Stefani et al. reported that an intracranial meningioma could metastasize to bilateral lungs presenting as defuse cystic lesions [7]. Given the above consideration, the scattered cystic lesions in our patient were classified as multiple intrapulmonary metastasis from primary pulmonary meningioma which has not previously been reported.

\section{Abbreviations}

CD: Clusters of Differentiation; $\mathrm{cm}$ : Centimeter; CT: computed tomography; EMA: Epithelial membrane antigen; IHC: Immunohistochemical;

MRI: Magnetic Resonance Imaging; PPM: primary pulmonary meningioma; PR: Progesterone receptor

\section{Acknowledgements}

We thank the help provided by department of pathology of West China hospital, Sichuan University.
Funding

None.

Availability of data and materials

All data generated or analyzed during this study are included in this published article.

\section{Authors' contributions}

XW and PL designed the study and drafted the manuscript. YF and PZ performed the histological examination of the lung biopsy and was a major contributor in writing the manuscript. PL and GC revised the manuscript. All authors read and approved the final manuscript.

\section{Ethics approval and consent to participate}

The study was performed in accordance with the Declaration of Helsinki and was approved by the West China Hospital of Sichuan University Biomedical Research Ethics Committee.

\section{Consent for publication}

The written informed consent was obtained from the patient to authorize us to share her clinical information and treatment details. 


\section{Competing interests}

The authors declare that they have no competing interests.

\section{Publisher's Note}

Springer Nature remains neutral with regard to jurisdictional claims in published maps and institutional affiliations.

\section{Author details}

'Department of Thoracic Surgery, West China Hospital, Sichuan University, Chengdu 610041, People's Republic of China. '2Department of Pathology, West China Hospital, Sichuan University, Chengdu 610041, People's Republic of China.

Received: 13 August 2018 Accepted: 27 December 2018

Published online: 08 January 2019

\section{References}

1. Raoof S, Bondalapati P, Vydyula R, et al. Cystic lung diseases: algorithmic approach. Chest. 2016;150(4):945-65.

2. Weiss A, Philippides D, Montrieul B, et al. Primary pulmonary meningioma: a rare, slow-growing tumor. J Radiol Electrol Arch Electr Medicale. 1952;4:701-3.

3. Satoh Y, Ishikawa Y. Primary pulmonary meningioma: ten-year follow-up findings for a multiple case, implying a benign biological nature. J Thorac Cardiovasc Surg. 2010;139(3):e39-40.

4. Incarbone M, Ceresoli GL, Di Tommaso L, et al. Primary pulmonary meningioma: report of a case and review of the literature. Lung cancer (Amsterdam, Netherlands). 2008;62(3):401-7.

5. Surov A, Gottschling S, Bolz J, et al. Distant metastases in meningioma: an underestimated problem. J Neuro-Oncol. 2013;112(3):323-7.

6. Bohra H, Rathi KR, Dudani S, Bohra A, Vishwakarma S, Sahai K. The study of mib-1 li and cd 34 as a marker of proliferative activity and angiogenesis in different grades of meningioma. J Clin Diagn Res 2016;10(8):Ec14-17.

7. Stefani A, Rossi G, Pecchi A, et al. An unusual case of cystic interstitial lung disease. Lancet. 2013;381(9873):1246.

Ready to submit your research? Choose BMC and benefit from:

- fast, convenient online submission

- thorough peer review by experienced researchers in your field

- rapid publication on acceptance

- support for research data, including large and complex data types

- gold Open Access which fosters wider collaboration and increased citations

- maximum visibility for your research: over $100 \mathrm{M}$ website views per year

At $\mathrm{BMC}$, research is always in progress.

Learn more biomedcentral.com/submissions 